Bolm. Zool.. Univ. S. Paulo $8: 189-213,1984$

\title{
OLIGOCHAETA MEGADRILI DA REGIÃO CENTRO-OESTE DE MATO GROSSO, BRASIL
}

GILBERTO RIGHI

Departamento de Zoologia, Instituto de Biociências, Universidade de São Paulo. (recebido em 26.III.1984)

RESUMO - Dezesseis espēcies de Oligochaeta são estudadas,Octochaetidae (5), Ocnerodrilidae (4) e Glossoscolecidae (7) Belladrilus ( $B$.) arua, sp. n., Rhinodrilus torquemadai, sp. n., Opisthodrilus adneae, sp. n., Glossodrilus tocantinensis pola, subsp.n. e Diaguita vivianeae, sp. n. são descritas Dichogaster gracilis é redescrita. Novas observações sobre Nematogenia lacuum e Goiascolex pepus sāo apresentadas.

ABSTRACT - Sixteen Oligochaeta species from Mato Grosso, Bra zil, are studyed, Octochaetidae (5), Ocnerodrilidae (4) and Glossoscolecidae (7) Belladrilus (B.) arua, sp. n., Rhino drilus torquemadai, sp. n., Opisthodrilus adneae, sp.n.,Glos sodrilus tocantinensis pola, subsp. $n$. and Diaguita vivia = neae, sp. n. are described. Dichogaster gracilis is redescri bed. New observations on Nematogenia lacuum and Goiascole $\bar{x}$ pepus are presented.

Como parte do Projeto Polonoreste, subvencionado pelo Conselho Nacional de Desenvolvimento Científico e Tecnológico $(\mathrm{CNPq})$, eu e o M.Sc. Rafael A. T. Guerra coletamos, em ju lho de 1983, oligoquetos terrícolas na região servida pelá

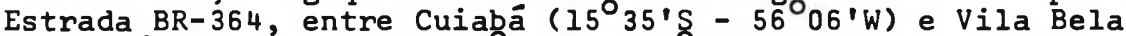
da Santíssima Trindade ( $\left.14^{\circ} 59^{\prime} \mathrm{S}-59^{\circ} 57^{\prime} \mathrm{W}\right)$. Os animais foram fixados e conservados em formalina $10 \%$ e estão depositados no Departamento de Zoologia da Universidade de São Paulo. 0 estudo foi feito por meio de dissecçōes e cortes histológi cos seriados, $12 \mu \mathrm{m}$, corados pelo metodo tríplice de Mallory.

\section{Localidades de coleta}

A. Serra da Campina (aproximadamente $16^{\circ} 20^{\prime} \mathrm{S}-57^{\circ} 30^{\prime} \mathrm{W}$ ), solo arenoso de cor marrom, com mata secundária.

B. Cáceres $\left(16^{\circ} 07^{\prime} \mathrm{S}-57^{\circ} 0^{\prime} \mathrm{W}\right)$, solo arenoso de cor cinza, antigo pomar abandonado, com mangueiras (Anacardiaceae, Mangifera indica), próximo de alagado. 
C. Sonho Azul $\left(15^{0} 47^{\prime} \mathrm{S}-58^{\circ} 11^{\prime} \mathrm{W}\right)$, solo arenoso e rico em hu mus, em horta.

D. Tabuleta $\left(15^{\circ} 50^{\prime} \mathrm{S}-58^{\circ} 20^{\prime} \mathrm{W}\right)$, solo argilo-arenoso com Gra mineae.

E. Pontes e Lacerda $\left(15^{\circ} 12^{\prime} \mathrm{S}-59^{\circ} 20^{\prime} \mathrm{W}\right)$, solo arenoso de cor cinza, com Gramineae, próximo de alagado.

F Pontes e Lacerda ( $150_{12}$ S $\left.-59^{\circ} 20^{\prime} \mathrm{W}\right)$, solo preto, muito $\underline{\mathrm{u}}$ mido, com Gramineae, próximo de alagado do Rio Guaporé.

G. Estrada Pontes e Lacerda - Vila Bela da Santissima Trinda de, $\mathrm{Km} \mathrm{55}$. Fazenda Lagoa do Encanto (aproximadamente $15^{\circ}$ $03^{\prime} \mathrm{S}$ - 59 $\left.50^{\prime} \mathrm{W}\right)$, solo preto, úmido, com Gramineae, próximo de lagoa.

H. Estrada Pontes e Lacerda - Vila Bela da Santíssima Trinda de, $\mathrm{Km} 60$, Fazenda Lagoa do Encanto (aproximadamente $15 \overline{0}$

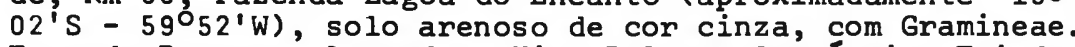

I. Estrada Pontes e Lacerda - Vila Bela da Santíssima Trinda de, $\mathrm{Km} 65$, Fazenda Arrozal (aproximadamente 15\%01's - 59 $54^{\prime}$ 'W), solo preto, com Gramineae, periodicamente inundado na margem de lagoa.

J. Vila Bela da Santissima Trindade ( $\left.14^{\circ} 59^{\prime} \mathrm{S}-59^{\circ} 57^{\prime} \mathrm{W}\right)$, entrada da cidade, solo arenoso, com Gramineae, próximo de alagado.

\section{Octochaetidae}

Dichogaster affinis (Michaelsen, 1890)

Benhamia affinis Michaelsen, 1890:29, est. 4, fig. 20.

Dichogaster affinis; Righi et all. 1978:38 (bibliografia); Righi, 1984:17, figs. 1-2.

Material - Localidade E, 1 clitelado (ZU-741).

\section{Dichogaster bolaui (Michaelsen, 1891)}

Benhamia bolavi Michaelsen, 1891:307, figs. 1-2.

Dichogaster bolaui; Righi et all. 1978:38 (bibliografia); Ri ghi, $1984: 18$, figs. 3-4.

Material - Localidade B, I clitelado (ZU-737) Localidade J, 1 clitelado (ZU-738)

Espécie antropocórica, circuntropical. 0 animal de B é anormal, o poro feminino ünico abre-se no centro de uma papi la arredondada, lateral à cerda $b$ esquerda de XIV.

Dichogaster gracilis (Michaelsen, 1892) (Figs. 1-7)

Benhamia gracilis Michaelsen, 1892:258, figs. Cl-2

Benhamia pallida Michaelsen, 1892:258, figs. Bl-2.

Benhamia sp. Horst, 1899:27, figs. 1-3.

Dichogaster gracilis; Michaelsen, 1900:350; 1907:13; 1910: 
$1 ; 1911: 32 ; 1913$ a:147; 1916:19; 1922:18; 1928:8; 1935:54; Cognetti, 1908:83.

Dichogaster pallida; Michaelsen, 1900:353.

Material - Localidade A, 1 clitelado (ZU-744). Localidade J, I clitelado $(\mathrm{ZU}-743)$.

Desçrição - Não obstante ter sido encontrada várias vezes, a espécie está insuficientemente descrita e figurada e pertence a um dos gêneros de oligochaeta mais rico em espécies, daí ser necessário descrever o meu material.

Comprimento $25-40 \mathrm{~mm}$. Diāmetro na região média 1,0 1,2 mm. Número de segmentos 109-124. Pigmento falta. Prostômio irreconhecível, invaginado com parte do peristómio. Sulco $1 / 2 \mathrm{mal}$ perceptivel. Cerdas dispostas em 8 séries longitu dinais regulares a partir de II, as de XVII e XIX transfor = mam-se em genitais, faltam em XVIII. Na região média do corpo, segmentos XXX-XL, $a a: a b: b c: c d: d d=6,5: 1,0$ : $5,0: 1,0: 47,5$. As cerdas comuns são sigmóides, com ligeiro espessamento submediano e ápice liso. Na regiăo média do

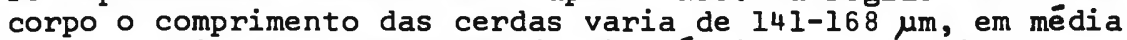
$160 \mu \mathrm{m}$. Clitelo em XIII-XXI (= 9), túrgido, sulcos intersegmentares irreconhecíveis e cor amarela como a do ne 260 de Séguy (1936). O clitelo é anelar em XIII, para trás tem forma de sela com limite inferior pouco lateral à linha das cer das $b$ (Fig. 1). Poros prostäticos pares no equador de XVII e XIX, em linha com $a b$. Cada poro está associado com uma papila circular, pequena, que contém um par de cerdas genitais

Os poros de cada lado são unidos por um sulco seminal delgado e arqueado em direção à linha média ventral, mais em XVIII. A área ao redor dos poros prostáticos e dos sulcos se minais é túrgida, esbranquiçada e confluente na linha médiáa ventral, originando um campo genital masculino em forma de haltere. Uma papila ovóide ocupa toda a face ventral de XIV, transportando medianamente o par de poros femininos na linha $a b$. Dois pares de poros de espermatecas abrem-se em $a b 7 / 8$ e $8 / 9$, tềm margem pouco túmida de cor branca leitosa.

0 primeiro septo é o 7/8; os $9 / 10-12 / 13$ são espessos e musculosos, os demais são frägeis. Duas moelas volumosas e de parede fortemente muscular fundem-se entre si anteriormen te ao septo $7 / 8$ Trềs pares de gländulas calcíferas situam se em XV-XVII, elas tornam-se maiores de diante para trás; 0 primeiro par e pequeno e arredondado e o terceiro grande e reniforme. 0 intestino inicia-se em XVIII. Cecos intestinais faltam. O tiflosole é uma lámina ondulada, tão alta quanto a metade do diâmetro intestinal. Corações situam-se em VIII XII, os de VIII e IX são delgados, os de $X$ e XI são 2 vezes mais volumosos e os de XII estão bastante dilatados pelo acû mulo de sangue, atingindo volume igual ao do vaso dorsal. Dé XV ou XXI para trás há 4 pares de nefrídios discoidais ou grosseiramente quadrangulares por segmento, os pares dorsal e ventral são os menores. Para a frente os nefrídios sảo pequenos, sem depósito de gordura.

Dois pares de testículos e de funis seminais encontramse livres em $X$ e XI. Vesiculas seminais faltam. Dois pares 
Estampa 1

Dichogaster gracilis

Fig. 1 - face ventral dos segmentos XII-XXII;

Fig. 2 - espermateca, preparação glicerínica;

Fig. 3 - dupla de cerdas genitais de um exemplar;

Fig. 4 - ápice das mesmas;

Fig. 5 - dupla de cerdas genitais de outro exemplar;

Fig. 6 - ápice das mesmas;

Fig. 7 - prōstata. 

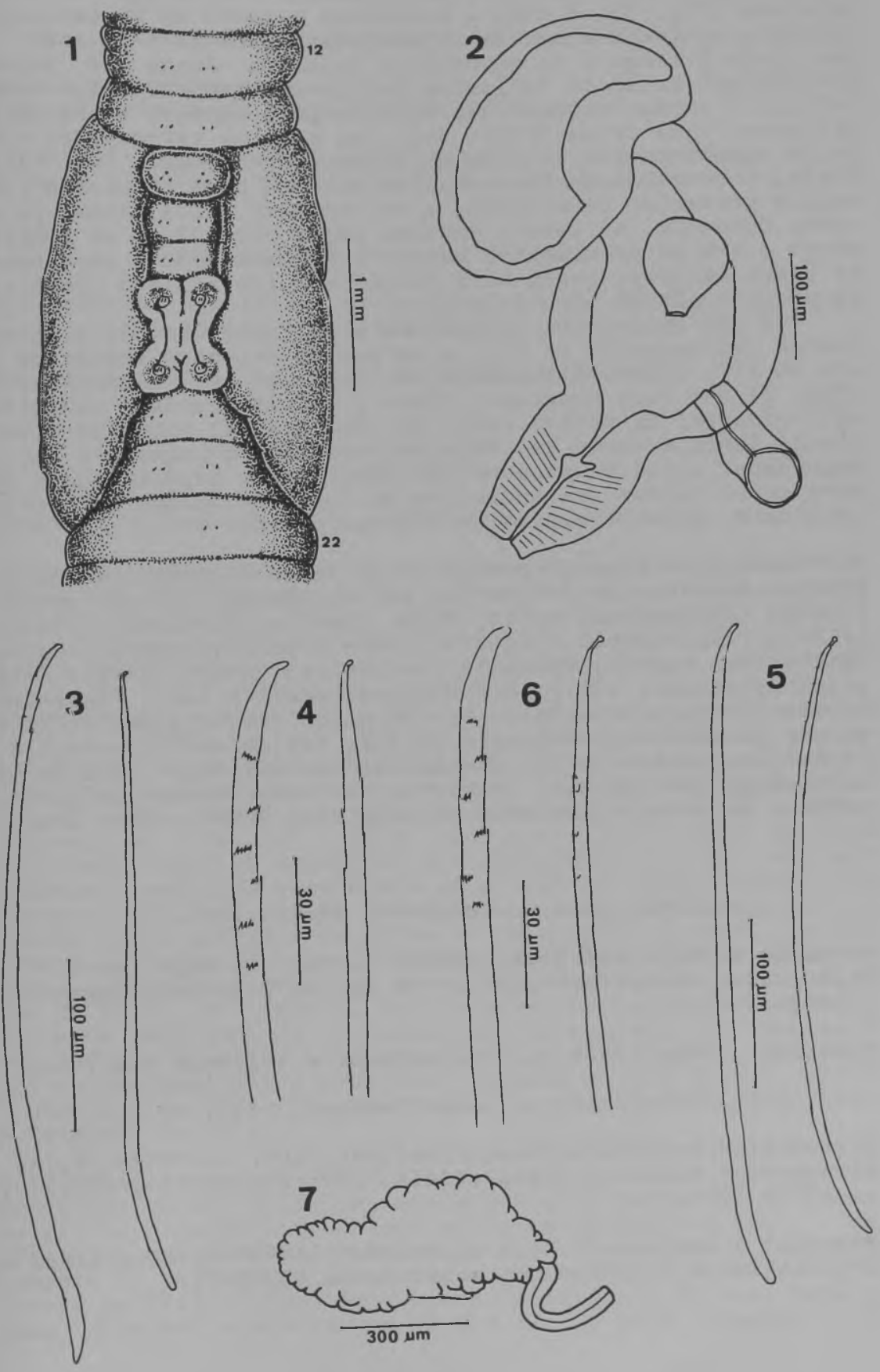
de próstatas restringem-se aos segmentos XVII e XIX. Em cada próstata (Fig. 7), o duto é musculoso e curvo em U, seu comprimento equivale à metade do comprimento da parte glandu lar. Esta e larga e de superfície lobulada. Junto aos dutos prostáticos estäo os folículos das cerdas genitais. Em cada tufo hả 2 cerdas maduras que diferem pelo tamanho e ora mais ora menos pela forma (Figs. 3-6). As maiores atingem 356-419 $\mu \mathrm{m}$ de comprimento e 9-10 $\mu \mathrm{m}$ no diàmetro proximal. Seu $1 / 5$ distal é ornamentado com entalhes abertos para o ápice e de margem posterior serrilhada, a extremidade apical forma pe queno cotovelo. As cerdas menores medem 322-373 $\mu \mathrm{m}$ de compri mento e 6-8 um de diâmetro basal. A ornamentação é sèmelhante à das maiores, porém mais tênue, o ápice afilado termina em pequeno nódulo algo lateral.

Um par de ovários flabelares e de funis femininos encon tra-se ventralmente em XIII e um par de ovisacos cheios de o vos em XIV, lätero-dorsalmente ao esôfago. As espermatecas (Fig. 2) tem duto muscular, curto e ampola grande, dividida em 2 câmaras. Da metade basal da câmara ectal parte um diver tículo longo e curvo que termina numa càmara pequena e ar redondada, cheia de espermatozóides. Em uma espermateca a câ mara ectal contem uma estrutura em forma de balão, de paredé brilhante, provavelmente um espermatóforo.

Distribuição - Espécie peregrina de vasta distribuição na $\bar{A}$ frica e América. Na Âfrica foi assinalada em Sierra Leone, Libéria (Michaelsen, 1922), Togo, Nigéria (Michaelsen, 1892; 1913a), I Iha Annobon (Cognetti, 1908), Gabão, Congo, Zaire (Michaelsen, 1935), Tanzania (Michaelsen, 1910; 1911) e Etió pia (Michaelsen, 1907) Dichogaster gracilis var. metandra Omodeo, 1973, com um ünico par de sacos testiculares em XI e um par de vesiculas seminais em XII, foi descrita da Angola. $\mathrm{Na}$ América a espécie foi assinalada nas Antilhas: Ilha Saint Barthelemy (Michaelsen, 1916), no Suriname: Paramaribo(Horst, 1899) e no Brasil: Amazonas (Michaelsen, 1928) e Mato Gros so.

\section{Dichogaster modiglianii (Rosa, 1896)}

Benhamia modiglianii Rosa, 1896:510, est. l, figs. la-b. Dichogaster modiglianii; Righi et all.1978:38 (bibliografia); Righi, 1980.

Material - Localidade A, 7 clitelados e 4 jovens (ZU-745)

$$
\text { Dichogaster saliens (Beddard, 1892) }
$$

Microdrilus saliens Beddard, 1982:683, est. 46, figs. 8,13. Dichogaster saliens; Righi et all. 1978:39 (bibliogrăfia); $1980 ; 1984: 19$.

Material - Localidade E, 5 clitelados (ZU-740). Localidade J, 14 clitelados e 17 maduros aclitelados (ZU-742) 


\section{Ocnerodrilidae \\ Eukerria eiseniana (Rosa, 1895)}

Kerria eiseniana Rosa, 1895:2.

Eukerria eiseniana; Righi, 1980 (bibliografia).

Material - Localidade B, 1 clitelado, 1 maduro aclitelado e 1 jovem (ZU-746) Localidade E, 2 clitelados (ZU-739).

\section{Gordiodrilus habessinus Michaelsen, 1913}

Gordiodrilus habessinus Michaelsen, 1913b: 5, fig. 2, est. II, figs. 30-31; 1915:218; Righi, 1980, figs. 30-31.

Material - Localidade B, 2 clitelados (ZU-736)

Belladrizus (B.) arua, sp. n.

(Figs. 8-9)

Material - Localidade E, 1 clitelado (ZU-742)

Descrição - Comprimento $19 \mathrm{~mm}$. Diâmetro na região média do corpo $840 \mathrm{\mu m}$. Pigmento falta. Nümero de segmentos 84 . Prostô mio epilobo aberto. Cerdas dispostas em 4 pares de séries longitudinais regulares a partir de II. As cerdas $b$ de XVII estáo deslocadas medialmente, saindo lado a lado com as cerdas $a$. Em XVIII faltam as cerdas $b$ e só è visivel a cerda $a$ esquerda. As cerdas são sigmóides, alongadas, comprimento 119 $-129 \mu \mathrm{m}$, nódulo no terço distal, äpice unicúspide e porção subapical com algumas cicatrizes semilunares rasas, de mar gem lisa ou crenulada e abertas para o ápice. Na região mé dia do corpo, segmentos XXX-XL, as relaçčes entre as cerdas são $a a: a b: b c: c d: d d=5,0: 1,0: 5,5: 1,0: 15,3$ 0 clitelo ocupa os segmentos $1 / 2$ XIII-XX $(=71 / 2)$, tem cor amarela alaranjada semelhante ao no 199 de Séguy (1936) e forma de sela com limite inferior na linha das cerdas $b$. Um par de poros prostáticos situa-se no equador de XVII, pouco lateral à linha de $b$, em ligeira depressão no ápice de papilas arredondadas. 0 par de poros masculinos situa-se no equa dor de XVIII, na linha $b$. Unindo os poros masculino e prostā ticos de cada lado há um sulco seminal estreito e profundo com a forma da letra $L$ invertida (Fig. 8) A área marginal dos sulcos seminais é tumefata, estende-se por $2 / 3$ de XVIII e continua ao redor de cada papila prostática, ocupando toda a extensão de XVII.

Os septos 6/7-8/9 são bastante espessos e musculosos, 0 $9 / 10$ pouco menos e os demais são delgados Glândulas septais encontram-se até VIII. Uma moela bem diferenciada, em forma de cilindro largo e musculoso situa-se em VII. Um par de glândulas calcíferas arredondadas abre-se ventral e posteriormente no esôfago em IX. A transição esôfago-intestino situa-se em XIII. Tiflosole e cecos intestinais faltam. Cora ções volumosos encontram-se em X e XI. Em cada segmento há 


\section{Estampa 2}

\section{Belladrilus (B.) arua}

Fig. 8 - face ventral dos segmentos $\mathrm{XV}-\mathrm{XX}$;

Fig. 9 - espermateca, preparação glicerínica;

Rhinodrilus torquemadai:

Fig.10 - face ventral dos segmentos XV-XXX;

Fig.l1 - glândula calcífera;

Fig.12 - espermateca;

Fig.13 - porção ental da espermateca, preparação glicerínica. 
8

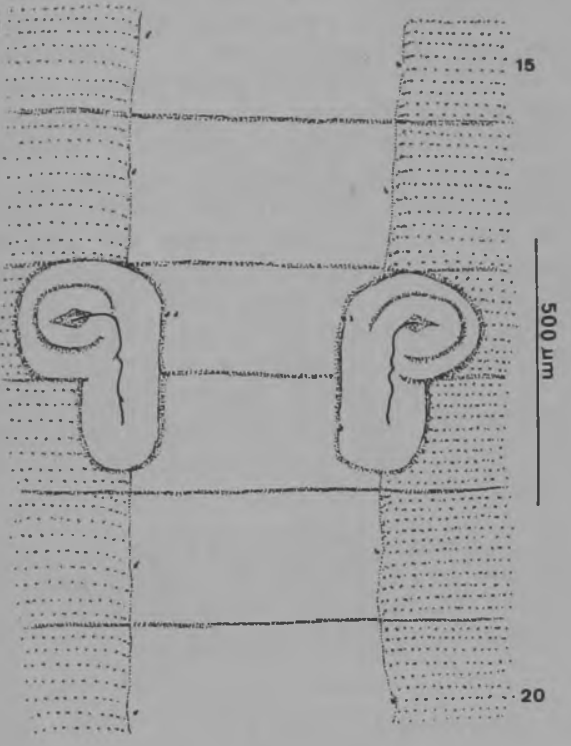

9

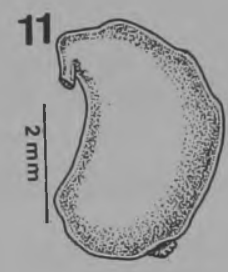

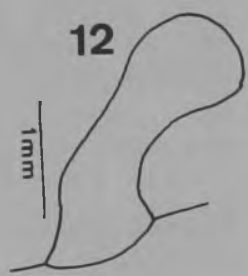
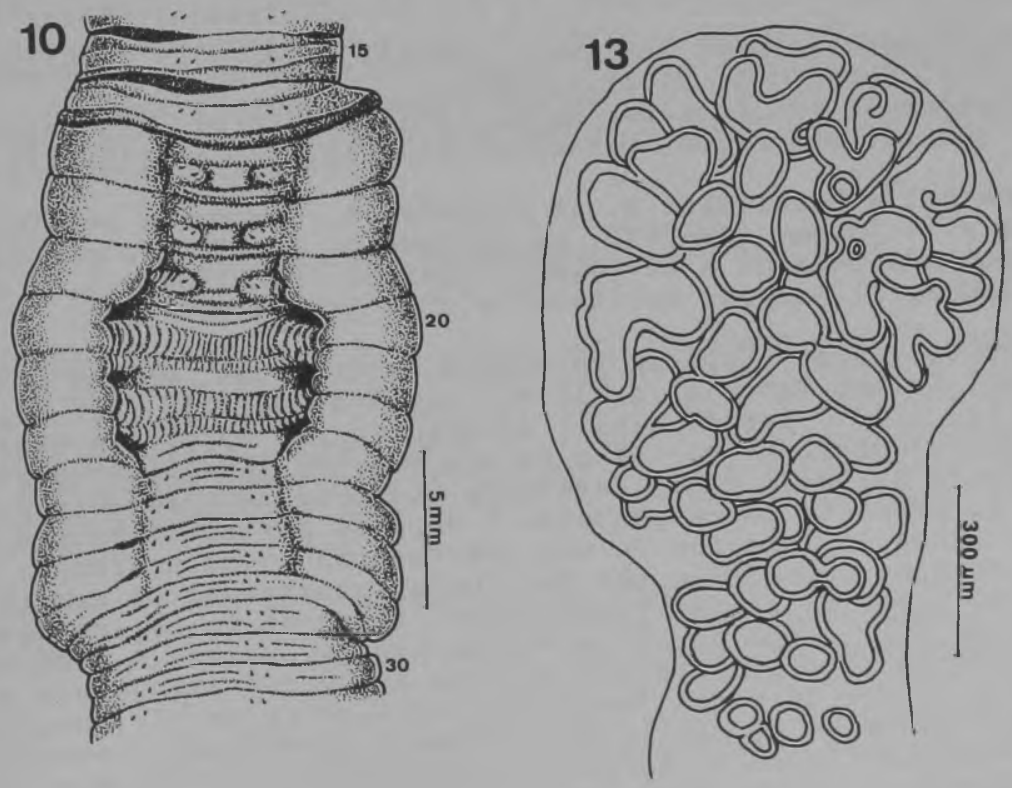
um par de nefrídios avesiculados, nefridióporos não foram vistos. Um par de testículos e de funis seminais encontram se livres na cavidade de $X$. Um par de vesiculas seminais grandes e lobuladas situa-se em XI. O par de próstatas tubulares de XVII faz vărias alças sob o intestino até o segmento XXIV Em cada próstata o duto é täo longo quanto 2 segmen tos, não apresenta dilatação ectal e seu diametro equivale à metade do diámetro da parte glandular. Um par de ovários pren de-se ventral e posteriormente em $12 / 13$, tem forma de lâmina larga com os óvulos amadurecendo em direção à margem posterí or. Um par de espermatecas salienta-se na cavidade do corpo em IX e abre-se por poros inconspícuos em $8 / 9$, na linha das cerdas $c$. Em cada espermateca (Fig. 9) a ampola é ovóide e o duto mais estreito, cerca de 1,5 vezes mais longo que a ampo la e dobrado em cotovelo. 0 lumem do duto é delgado, dilatan do-se numa câmara na região do cotovelo. o terço ectal do du to envolvido por espessa camada muscular.

Consideraçōes - Belzadrilus ( $B$. ) arua aproxima-se de $B$. (B.) jimi Righi, 1980, distinguindo-se pela forma do campo geni tal masculino e das espermatecas. O nome da nova espécie é o de uma tribo indígena do Rio Guaporé (Mato Grosso)

\section{Nematogenia Zacuum (Beddard, 1893)}

Pygmaeodrilus Zacuum Beddard, 1893:259, est. 26, figs: 13-16. ocnerodrilus (Nematogenia) lacuum var. panamaensis Eisen, 1900:127, est. 9, figs. 55-65,67, est. 11, figs. $114-$ 116.

Nematogenia Zacuum; Jamieson, 1966:95, figs. 1-3 (bibliografia, descrição, distribuição).

Nematogenia panamaensis; Gates, 1962:257, figs. A-B (bibliografia, descrição, distribuição); 1972:272; 1979:163)

Material - Localidade B, 14 clitelados, 5 maduros aclitela dos e 26 jovens ( $Z U-747$ ). Localidade D, 13 clitelados, $52 \mathrm{ma}$ duros aclitelados e 22 jovens ( $Z U-748)$ Localidade $E, 2$ cli= telados, 12 maduros aclitelados e 11 jovens ( $\mathrm{ZU}-749)$.

Considerações - Espécie peregrina pantropical, bastante vari àvel. Em meu material o clitelo situa-se em XIII, XIV - XXV $(=11,12)$. O par de canais deferentes näo apresenta espes samento ectal. Em cortes e em preparaçöes glicerínicas verifica-se gue cada canal deferente contorna lateralmente o duto da prostata correspondente e abre-se posteriormente a este, ambos no interior de uma reentrância pouco profunda, que se abre na superfície por uma fenda transversal de margem tû mida. 0 par de fendas transversais situa-se em $a b$, no equa dor de XVII, cada no aṕice de uma papila ovalada e pode continuar-se lateralmente por delgado sulco que atinge até a li nha $c$. $O$ par de poros femininos localiza-se em XIV, pouco an teriormente às cerdas $b$. Meus animais apresentam caracteres intermediários entre lacuum e panamaensis, justificando in terpretar a ültima como jovem sinônimo. 


\section{Glossoscolecidae}

Goiascolex pepus Righi, 1972

Goiascolex pepus Righi, 1972:153, figs. 4-6.

Material - Localidade G, 2 maduros aclitelados e 7 jovens ( $\mathrm{ZU}$ -720)

Considerações - A descrição original baseou-se em 1 exemplar clitelado da região do Rio Araguaia, Mato Grosso, aproximada mente $13^{\circ} 21^{\prime} \mathrm{S}-50^{\circ} 48^{\prime} \mathrm{W}$. Acrescento as observações efetuadas nos animais da presente coleção.

Nos 2 animais maduros as cerdas ventrais de XVII-XVIII e XX-XXV são envolvidas por áreas diferenciadas estreitas e comuns a cada dupla de cerdas. Não há áreas glandulares nos septos. Três pares de glândulas calciferas piriformes abremse dorso lateralmente no esôfago em VII-IX. As glândulas são aproximadamente do mesmo tamanho, mas os dutos tornam - se mais longos e finos do primeiro ao terceiro par. A estrutura das glândulas é tubular dicotômica, com túbulos mais largos na face oposta ao esôfago. O intestino dilata-se bruscamente em 1/2 XXIV. 0 tiflosole inicia-se em XXV e tem a forma de uma lâmina mais alta do que o diāmetro intestinal e dobrada em $S$. Cecos intestinais faltam. 0 vaso dorsal simples liga se ao vaso ventral por 3 pares de delgados corações laterais em VII-IX. 0 vaso supra-esofágico estende-se de VII-XI e comunica-se com o vaso ventral por 2 pares de volumosos cora ções látero-intestinais em X e XI. Uma espessa e larga faixa glandular esbranquiçada situa-se entre a parede do corpo e a cadeia nervosa em XVI-XXVI, recobrindo as câmaras copulató rias. As câmaras copulatórias prendem-se ventralmente em $1 / 2$ $\mathrm{XIX}-\mathrm{XX}$, são arredondadas e com ampla cavidade central medial. mente intercomunicante.

\section{Rhinodrilus torquemadai, sp. $\mathrm{n}$.} (Figs. 10-14)

Material - Localidade B, 3 clitelados fragmentados, 2 madu ros aclitelados e 2 casulos ( $\mathrm{ZU}-719 \mathrm{~A}-\mathrm{B}$ ) Localidade $\mathrm{G}, 2$ cli telados fragmentados, 2 maduros aclitelados, 6 jovens e 2 ca sulos (ZU-718A-B). Localidade H, 2 clitelados ( 1 fragmenta do) e 2 jovens (ZU-717). Localidade I, 10 clitelados ( 8 frag mentados), 3 maduros aclitelados, 4 jovens e 2 casulos ( $\mathrm{ZU}-$ 716A-C)

Descrição - Comprimento 260-270 mm. Diâmetro preclitelar 7$7,5 \mathrm{~mm}$, clitelar $12-13 \mathrm{~mm}$, mediano $8,5-9 \mathrm{~mm}$, posterior $6-7$ mm. Nümero de segmentos 260-294. Cor dorsal verde escura semelhante ao no 314 de Séguy (1936), ventre verde amarelado como o no 222, face ventral de VII-IX e do clitelo esbranqui çadas. Prostómio e segmentos I-II invaginados, III com numerosos sulcos longitudinais em toda a superfície, IV-X, XI de superfície lisa, os demais em geral bianelares. Cerdas dis - 
postas em 4 pares de séries longitudinais regulares, as ventrais iniciam-se em IV-VI e as laterais em XIV-XVI. As cer das $a$ e $b$ de XX-XXII estão deslocadas lateralmente. As relações entre as cerdas na região média do corpo de 4 exempla res estão na Tabela l. As cerdas normais são sigmóides, com nódulo bem diferenciado e $01 / 3$ apical ornamentado por 4 séries alternas de escavações semicirculares largas, 0 número de escavações por série varia de 5-7 Na regiăo média do corpo o comprimento das cerdas a e $b$ varia de 835-951 um, em média $881 \mu \mathrm{m}$ e das cerdas $c$ e d varia de 591-759 $\mu \mathrm{m}$, em mé dia $678 \mu \mathrm{m}$. As cerdas ventrais de VII-VIII e XIX-XXII transformam-se em genitais. Elas são retas na maior parte e cur vas na extremidade proximal, seus $4 / 5$ distais apresentam escavações semilunares dispostas em 4 séries alternas. Em VIIIX o comprimento das cerdas genitais varia de $1,9-2,3 \mathrm{~mm}$ e 0 número de escavaçōes por série é 24-28. Em XIX-XXII o compri mento das cerdas $\bar{e} 2,9-3,3 \mathrm{~mm} e$ o número de escavaçōes por série 31-34. Nos animais maduros a face ventral de VII-IX, $1 / 2 \mathrm{X}$ é türgida. 0 clitelo ocupa os segmentos XVII-XXV, XXVI $(=9,10)$, tem forma de sela com limite inferior pouco acima da linha $b$ e mais espesso em XIX, XX-XXII, XXIII (Fig. 10). Reentrâncias profundas encontram-se lateralmente à linha $b$ em XX-XXII, separadas entre si por saliências oblíquas, percorridas por pregas longitudinais, dispostas nos 2 lados dos sulcos intersegmentares $20 / 21$ e $21 / 22$, mais largas na metade posterior de XX e XXI. Papilas ovaladas contêm as cerdas a e $b$ de XVII-XIX. Āreas circulares diferenciadas, pouco salientes, circundam cada cerda ventral de XX-XXII e cada dupla em VII-VIII.

Tabela 1 - Rhinodrilus torquemadai, relações entre as cerdas dos segmentos XL-L em 4 exemplares da Localidade I.

\begin{tabular}{|c|c|c|c|c|c|c|c|c|c|}
\hline xemplar & $a a$ & & $a b$ & & $b c$ & & $c d$ & & $d d$ \\
\hline $\begin{array}{c}\text { A } \\
\text { B } \\
\text { C } \\
\text { D } \\
\text { Média }\end{array}$ & $\begin{array}{l}8,66 \\
9,00 \\
7,71 \\
9,40 \\
8,69\end{array}$ & $\begin{array}{l}: \\
\vdots \\
\vdots \\
\vdots\end{array}$ & $\begin{array}{l}1,00 \\
1,00 \\
1,00 \\
1,00 \\
1,00\end{array}$ & $\begin{array}{l}: \\
\vdots \\
\vdots \\
:\end{array}$ & $\begin{array}{r}11,66 \\
10,50 \\
8,85 \\
11,40 \\
10,60\end{array}$ & $\begin{array}{l}: \\
\vdots \\
\vdots \\
\vdots\end{array}$ & $\begin{array}{l}0,66 \\
0,66 \\
0,64 \\
0,70 \\
0,66\end{array}$ & $\begin{array}{l}: \\
: \\
: \\
:\end{array}$ & $\begin{array}{l}23,16 \\
23,83 \\
19,00 \\
25,40 \\
22,84\end{array}$ \\
\hline
\end{tabular}

Os septos a partir de 6/7 têm a forma de longos cones interpenetrados, que se tornam sucessivamente menos distendi dos para trás e planos a partir de 18/19. Os septos de $18 / 1 \overline{9}$ para trás são delgados e semelhantes entre si, para diante tornam-se pouco mais espessos e musculosos. A volumosa massa faríngea atinge atê oespaço correspondente ao segmento VII externo. Segue-se o volumoso esôfago anterior que se abre nu ma moela arredondada e muito musculosa em VI que, devido à forma dos septos, corresponde externamente aos segmentos XIXII. O esófago posterior é delgado e comunica-se com o volumoso intestino em XXVII. Três pares de glândulas calcíferas abrem-se dorso-lateralmente no esôfago em VII-IX. As glândulas (Fig. 11) são semelhantes entre si, piriformes, com dimi 
nuto apêndice lobular ental e de estrutura tubular paniculada. Ôs túbulos glandulares são largos e contêm cristais de calcário acumulados na metade ental das glāndulas. 0 tifloso le inicia-se com 0 intestino em XXVII e tem a forma de una lâmina mais alta que o diâmetro intestinal e dobrada em $\mathrm{S}$. Cecos intestinais faltam. Pares de massa glandulares arredon dadas e volumosas prendem-se na parede ventral do corpo e să lientam-se de cada lado do esôfago em XIX-XXII. Quatro pares de volumosos corações intestinais situam-se em X-XIII e 3 pa res de delgados coraçōes laterais em VII-IX. Em cada segmento há um par de holonefrídios vesiculados com nefridiooporos em cd ou d. Dois pares de testículos e de funis seminais mui to pregueados e de cor branca brilhante situam-se em X e XI, no interior de sacos testiculares. Os sacos testiculares simétricos fundem-se ventral e dorsalmente, os de XI envolvem as vesículas seminais desse segmento. Dois pares de vesicu las seminais quase retangulares encontram-se em XI e XII. Um par de ovários e de funis femininos situam-se em XIII,mas, de vido à forma cónica dos septos, correspondem externamente ao segmento XVI, de modo que os ovidutos curtos abrem-se em XVII, pouco atrás das cerdas $b$. Cada ovário tem a forma de uma lâmina larga e dobrada, com os ovos amadurecendo em dire ção à margem livve segundo faixas nítidas. Dois pares de poros de espermatecas crateriformes salientam-se na região pos terior de VII e VIII, na linha dos nefridiöporos. Em cada es permateca (Fig. 12) a região de adesão parietal è larga, segue-se um "duto" curto, reto ou curvo e uma "ampola" alargada. As espermatecas são estruturas compactas, de parede musculosa, mais espessa no "duto". A cavidade do "duto" e da am pola" não é simples, mas formada por um sistema complexo dé câmaras intercomunicantes (Fig. 13), mais numerosas na "ampo la" As câmaras não se salientam na superfície e estão che = ias de espermatozóides enovelados.

Casulos - Os casulos são ovóides, com o maior diāmetro pouco oblíquo em relação a linha que une os polos (Fig. 14). Nos 6 casulos observados, todos sem embriōes diferenciados, as mai ores medidas são semelhantes, em média 11,5 x 10,0 mm.

Considerações - $R$. torquemadai pertence ao grupo formado por $R$. appuni (Michaelsen, 1892), $R$. sieversi (Michaelsen, 1895)e $R$. romani Michaelsen, 1928) As 2 primeiras espécies são conhecidas da Venezuela: Puerto Cabello e a terceira do Brasil, Amazonas: entre S. Felipe e S. Gabriel no curso superior do Rio Negro. A nova espécie distingue-se das demais pela organização das espermatecas, ornamentação das cerdas genitais e presença de apendice nas glândulas calcíferas. 0 nome da nova especie é uma homenagem ao M.Sc. Rafael Angel Torquemada Guerra pelo seu inestimavel auxílio na coleta dos animais.

\section{Opisthodrilus borellii borellii Rosa, 1895}

Opisthodrilus borellii Rosa, 1895:2; 1896:130, figs. 9-12;Mi chaelsen, 1918:237; Stephenson, 1931:318; Righi, 1972:16I. 


\section{Estampa 3}

Rhinodrizus torquemadai

Fig. 14 - casulo.

opisthodrilus adneae

Fig. 15 - face ventral dos segmentos XXIII-XXX;

Fig. 16 - glândula calcífera;

Fig. 17 - espermateca de 6/7, preparação glicerínica;

Fig. 18 - idem de $7 / 8$.

Glossodrilus tocantinensis pola

Fig. 19 - face ventral dos segmentos XV-XXIII;

Fig. 20 - face ventral dos segmentos XVI-XXI de outro exemplar;

Fig. 21 - espermateca de 8/9; preparação glicerínica;

Fig. 22 - casulo. 


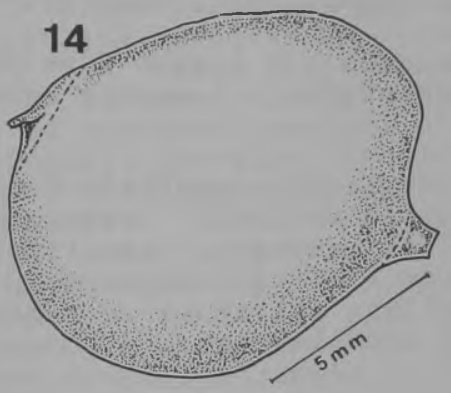

15
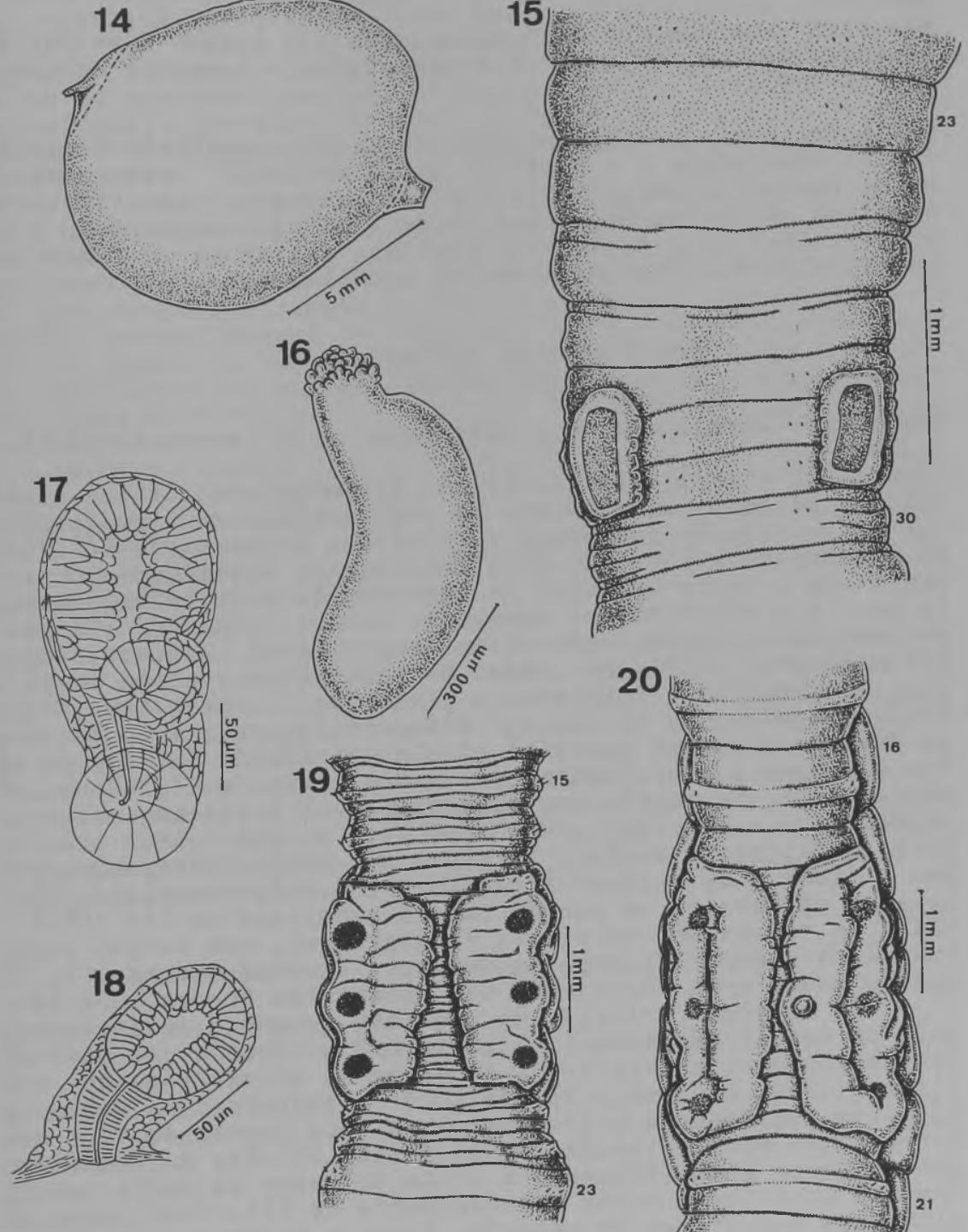
Opisthodrilus borellii borellii; Righi, 1980, figs. 41-43.

Material - Localidade B, 2 clitelados e 4 jovens (ZU-733). Lo calidade C, 4 clitelados ( 1 fragmentado) e 1 maduro aclitela do $(\mathrm{ZU}-730)$.

Considerações - A distribuição das papilas genitais é variāvel na subespécie e o materíal agora estudado assemelha-se ao de Cuiabà (Righi, 1980). Papilas genitais preclitelares envolvem as duplas de cerdas $a b$ de IX-X ( 3 exemplares), XXI (1), IX-X e ed de IX (2), papilas faltam (1). Papilas posclitelares faltam em todos os exemplares.

Opisthodrilus adneae, sp. n. (Figs. 15-18)

Material - Localidade B, 6 clitelados e 11 jovens (ZU-734)

Descrição - Comprimento 42-56 mm. Diâmetro preclitelar 1,6$1,8 \mathrm{~mm}$, clitelar $1,5-1,7 \mathrm{~mm}$, na região média do corpo 1,4 $1,6 \mathrm{~mm}$, na região posterior $1,1-1,2 \mathrm{~mm}$. Pigmento falta. Núme ro de segmentos 134-143. Prostomio curto, invaginado junta = mente com a parte anterior do segmento I. A superfície expos ta de I é percorrida por numerosos sulcos longitudinais pouco profundos. Um profundo sulco longitudinal, mediano e dorsal percorre I e II. As cerdas dispóem-se em 4 pares de sé ries longitudinais regulares a partir de II. Elas têm forma de $S$ alongado, com nódulo mal diferenciado no início do terço distal, a porção apical é lisa e unicúspide. Na região mé dia do corpo o comprimento das cerdas varia de 67-103 $\mu \mathrm{m}$, em média $84 \mu \mathrm{m}$. Na região dos segmentos $L-L X$ a relação entre as cerdas é $a a: a b: b c: c d: d d=14,5: 1,00: 14,2: 0,7$ : 43,0. 0 clitelo é anelar, túrgido, com sulcos intersegmentares nitidos e situado em XV-XXIII $(=9)$. Dois exemplares clitelados apresentam um par de traves pubertais em $1 / 2$ XXVII XXIX. As traves são espessas, retangulares, com margem pouco crenulada e superfície plana com àrea central escura (Fig.15) Quatro exemplares clitelados não apresentam traves pubertais. Os septos 6/7-10/11 são cônicos, longos e interpenetra dos, os demais são planos. 0 septo $6 / 7$ è tênue e de difícil reconhecimento, os seguintes espessam-se sucessivamente até $10 / 11,12 / 13$, os demais são delgados e frägeis. Uma moela cị líndrica, volumosa e muito musculosa localiza-se em VI, mas corresponde parietalmente aos segmentos VII-IX, X. 0 esôfago apresenta-se muito dilatado e cheio de terra na parte imedia tamente anterior à moela e dorsalmente em VII. Três pares dé glândulas calcíferas de tamanho, forma e estrutura semelhantes situam-se em VII-IX, abrindo-se ventralmente no esófago. As glândulas (Fig. 16) têm forma de banana, com apêndice ter minal grande e de superfície nodular. Sua estrutura é tubu lar dicotómica, 0 diametro dos túbulos é menor na parte voltada para o esôfago. A transição esôfago-intestino situa-se em XVII. O intestino dilata-se sucessivamente de XVII-XX, on de atinge o diametro normal posterior. Cecos intestinais faI 
tam. O tiflosole dorsal inicia-se em XXIII, sua parte anteri or, enrolada, projeta-se livre para a frente até a cavidade de XX. Para tras o tiflosole apresenta-se como una lámina do brada em $S$, quase tão alta quanto o diämetro intestinal. Dois pares de corações laterais volumosos situam-se em X e XI. Va so subneural presente. Em cada segmento há un par de holonefrídios vesiculados, os nefridiöporos são intersegmentares na linha $c d$.

Dois sacos testiculares ventrais em XI fundem-se entre si e envolvem a base dos coraçōes intestinais desse segmen to. O par de vesículas seminais é tubular, com constriçōes nos septos e estende-se dos lados do esốfago até XIV, XV Ca da duto masculino, cheio de espermatozóides, corre sobre a parede ventro-lateral do corpo até $28 / 29,1 / 2$ XXIX, onde pene tra na região da trave pubertal correspondente e se abre pelo poro masculino microscópico. Dois pares de espermatecas diminutas abrem-se em 6/7 e 7/8 na linha das cerdas laterais. Cada espermateca, saliente na cavidade do corpo, é envolvida por um revestimento conjuntivo-muscular, de modo que externa mente não se distingue duto e ampola, so visíveis por trans= parência. A ampola e simples ou dividida em 2 câmaras (Figs. 17-18), internamente é revestida por um epitélio alto e glan dular que oblitera quase todas a cavidade. Não vi espermatozóides nas espermatecas.

Consideraçōes - Do gênero Opisthodrilus Rosạ, 1895 são conhe cidas 2 espécies: 0 . borellii, com 2 subespécies 10 . borel = $l_{i i}$ borellii Rosa, 1895) e 0 . borellii tuberculiferus Righi, 1980 ) e 0 . rhopalopera Cognetti, 1906. 0 . adneae distingue se das outras 2 pela posição do clitelo, das traves puber tais, dos poros masculinos e pelo número de espermatecas. E interessante notar a ausência de traves pubertais em alguns animais clitelados de 0 . adneae em contraste com as demais Glossoscolecidae, onde as traves pubertais diferenciam-se an tes do clitelo durante o processo de maturação.

\section{Pontoscolex (P.) corethrurus (Muller, 1857)}

Lumbricus corethrurus Mliler, 1857:113. Pontoscolex (P.) corethrurus; Righi, 1982; 1984:20.

Material - Localidade B, 20 clitelados, 2 maduros aclitela dos e 1 jovem ( $Z U-727)$. Localidade E, 39 clitelados, 1 jovem e 10 casulos ( $\mathrm{ZU}-724,725$ ) Localidade $F, 9$ clitelados e 1 casulo (ZU-729). Localidade J, 21 clitelados, 7 jovens e 2 casulos $(\mathrm{ZU}-726,728)$.

Glossodrilus tocantinensis pola, subsp. n. (Figs. 19-22)

Material - Localidade F, 12 clitelados ( 5 fragmentados) e 2 casulos (ZU-73I) Localidade J, I clitelado, 7 jovens e 4 ca sulos $(\mathrm{ZU}-732)$ 
Descrição - Comprimento 120-130 mm. Diâmetro preclitelar 2,2 $-2,4 \mathrm{~mm}$, no clitelo $2,6-2,7 \mathrm{~mm}$, na região média do corpo 1,6 $-1,8 \mathrm{~mm}$ e na região posterior $1,7-2,0 \mathrm{~mm}$. Pigmento falta. Nú mero de segmentos 226-279. Prostômio e parte de I invagina dos. Segmentos preclitelares e parte ventral dos clitelares com 3 ou mais ânulos, os demais de superfície lisa. Cerdas dispostas em 8 séries longitudinais regulares a partir de II, III. As relações entre as cerdas da região média (segmen tos $\mathrm{LX}-\mathrm{LXX})$ são $a a: a b: b c: c d: d d=19,2: 1,0: 4,5$ : 0,9 : 16,5 e na região posterior (segmentos CCL-CCLX) aa : $a b: b c: c d: d d=18,0: 1,0: 5,0: 0,8: 11,0$. As cerdas ventrais estão pouco deslocadas medialmente em XVII e faltam em XVIII-XX. As cerdas são sigmóides, alongadas, com pequeno nōdulo submediano e porção apical lisa e unicúspide. $0 \mathrm{com}$ primento das cerdas na região média varia de 154-180 $\mu \mathrm{m}$, em média $169 \mu \mathrm{m}$. 0 clitelo ocupa os segmentos XV-XXII $(=8)$, túr gido, com sulcos intersegmentares nitidos, em forma de selá com limite inferior na linha dos nefridióporos. Um par de traves pubertais espessas, largas e quase retangulares esten dem-se de $1 / 2$ XVII-I/2 XX, XX. Sua margem lateral é dupla, originando um sulco longitudinal em linha com $b$. A margem me dial é simples, aproximando-se da linha média véntral em XVIII ou XVIII-XIX (Figs. 19-20) A porção longitudinal e mediana das traves pubertais é ora mais ora menos deprimida Três pares de áreas circulares escuras, geralmente um pouco deprimidas, situam-se na metade lateral das traves pubertais em XVIII-XX. Uma papila hemisférica e escura encontra-se em $X I X$, na trave pubertal esquerda, próxima da margem medial,em todos os exemplares de F, falta no exemplar de $J$ Dos 12 ani mais de $F, 8$ apresentam uma papila semelhante, impar, ven tral e posterior em IX. Destes 8, um animal apresenta mais 1 par de papilas idênticas na metade anterior e ventral de IX, próximo da linha $a$, em 1 animal falta a papila esquerda do par e em outro a direita. Quatro exemplares de $\mathbf{F} \mathrm{e}$ único clitelado de $J$ não apresentam papilas em IX.

Os septos 6/7-10/11 são espessos, musculosos e cōnicos, os demais são frágeis e planos. A massa glandular faríngea es tende-se dorsalmente ao esôfago até a parte anterior da moela. A moela tem a forma de um cilindro curto, espesso e de parede muito musculosa, situa-se em VI mas, devido à forma dos septos, corresponde ao VIII parietal. Um par de glândulas calcîferas sésseis abre-se dorsalmente no esofago em XII. Ca da glândula compōe-se de uma parte glandular em XII-XIII , que se continua por um saco membranoso posterior até XVI. Á transição esôfago-intestino situa-se em 14/15.0 intestino tem diametro estreito até XXIII, onde se alarga no calibre normal posterior. O tiflosole dorsal inicia-se em XV, até XXVII, XXVIII apresenta-se como uma lámina espessa, de altura igual a $2 / 3$ do diâmetro intestinal, sua margem livre é re ta e a parede espande-se, formando câmaras justapostas que se alternam de cada lado. Para trás o tiflosole e simples, de contorno triangular nos cortes transversais e de altura equivalente a $1 / 3$ do diâmetro intestinal. Cecos intestinais faltam. Três pares de coraçōes laterais delgados encontram se em VII-IX e 2 pares de corações intestinais pouco volumosos em X-XI. Em cada segmento há um par de holonefrídios ve- 
siculados com nefridióporos intersegmentares situados pouco acima da linha de cerdas $b$. Um par de testículos e de funis seminais grandes e pregueados sao envolvidos por sacos testi. culares em XI. Um par de vesiculas seminais em forma de faixa estreita e achatada estende-se dorsalmente ao intestino a té XXIII. Um par de ovários diminutos encontra-se em XIII Trés pares de espermatecas de tamanho e forma semelhantes 10 calizam-se em VIII-X e abrem-se por poros microscópicos ná linha $b$ de 7/8-9/10. Cada espermateca (Fig. 21) tem forma de borduna, sem distinção externa entre duto e ampola. 0 epitélio interno é alto e irregular e o $1 / 3$ ectal é revestido por uma capa muscular.

Casulos - Os casulos (Fig. 22) são fusiformes, com um fila mento polar longo e delgado e outro curto, largo e achatado. A membrana de revestimento é incolor e transparente, mesmo nos que têm embrião bem diferenciado, as extremidades e fila mentos polares são marrons. Os maiores diâmetros dos casulos varia de $3,9 \times 2,8 \mathrm{~mm}$ a $5,3 \times 2,5 \mathrm{~mm}$.

Considerações - Glossodrilus tocantinensis tocantinensis ( $\mathrm{R}$ ghi, 1972) é conhecida apenas pela descrição original basea da em animais provenientes do Pará: Cametả e Mocajuba. A nova subespécie difere da forma típica principalmente pelas traves pubertais e papilas copulatórias. 0 nome da nova subespécie é uma combinação das sillabas iniciais da localidade Pontes e Lacerda, onde foi coletado o maior número de exem plares.

\section{Diaguita vivianeae, sp. n.} (Figs. 23-30)

Material - Localidade H, 5 clitelados, 2 jovens e 3 casulos (ZU-722). Localidade J, 27 clitelados, 3 jovens e 13 casulos $(\mathrm{ZU}-721,723)$

Descrição - Comprimento 72-120 mn. Diâmetro anterior 3,7 4,0 mm, no clitelo 3,8-4,1 mm, na região média do corpo 3,4$4,0 \mathrm{~mm}$, na região posterior $2,9-3,2 \mathrm{~mm}$. Cor no dorso marrom avermelhada semelhante ao no 694 de Séguy (1936), desaparece nos animais conservados, ventre esbranquiçado. Clitelo marrom claro como o no 705. Número de segmentos 124-213. Prostô mio epilobo aberto. Segmento I com numerosos sulcos longitudinais, os dorsais prolongam-se no prostômio. Segmentos II IV e os do clitelo são simples, os demais com 3-4 ânulos. Cer das dispostas em 4 pares de serries longitudinais regulares, as ventrais iniciam-se em II e as laterais em III. As cerdas normais (Fig. 24) são sigmóides, espessas, com pequeno nódulo no terço distal e o quinto apical ornamentado por escavações curtas, finas, abertas para o ápice e mais numerosas na face côncava das cerdas. Na região média do corpo o compri mento das cerdas varia de $317-414 \mu_{2}$ em média $381 \mu m e^{\text {na }}$ região posterior de $388-445 \mu \mathrm{m}$, em média $406 \mu \mathrm{m}$. As relações entre as cerdas são, na região média do corpo (segmentos XLL), $a a: a b: b c: c d: d d=18,0: 1,0: 5,0: 1,0: 27,3$ e, 


\section{Estampa 4}

\section{Diaguita vivianeae}

Fig. 23 - face ventral dos segmentos VII-XVII;

Fig. 24 - cerda da região média;

Fig. 25 - espermateca de 7/8;

Fig. 26 - idem de $8 / 9$

Fig. 27 - corte transversal do duto da espermateca;

Fig. 28 - face interna da parede do corpo de XVIII-XXI;

Fig. 29 - glândula calcífera direita vista pela face esofágica;

Fig. 30 - casulo.

CC - câmara copulatória; CN - cadeia nervosa; LD - ligação com o vaso dorsal; LSB - ligação com o vaso subesofágico ; LSP - ligação com o vaso supra-esofágico; PG - parte glandu lar; SM - saco membranoso. 

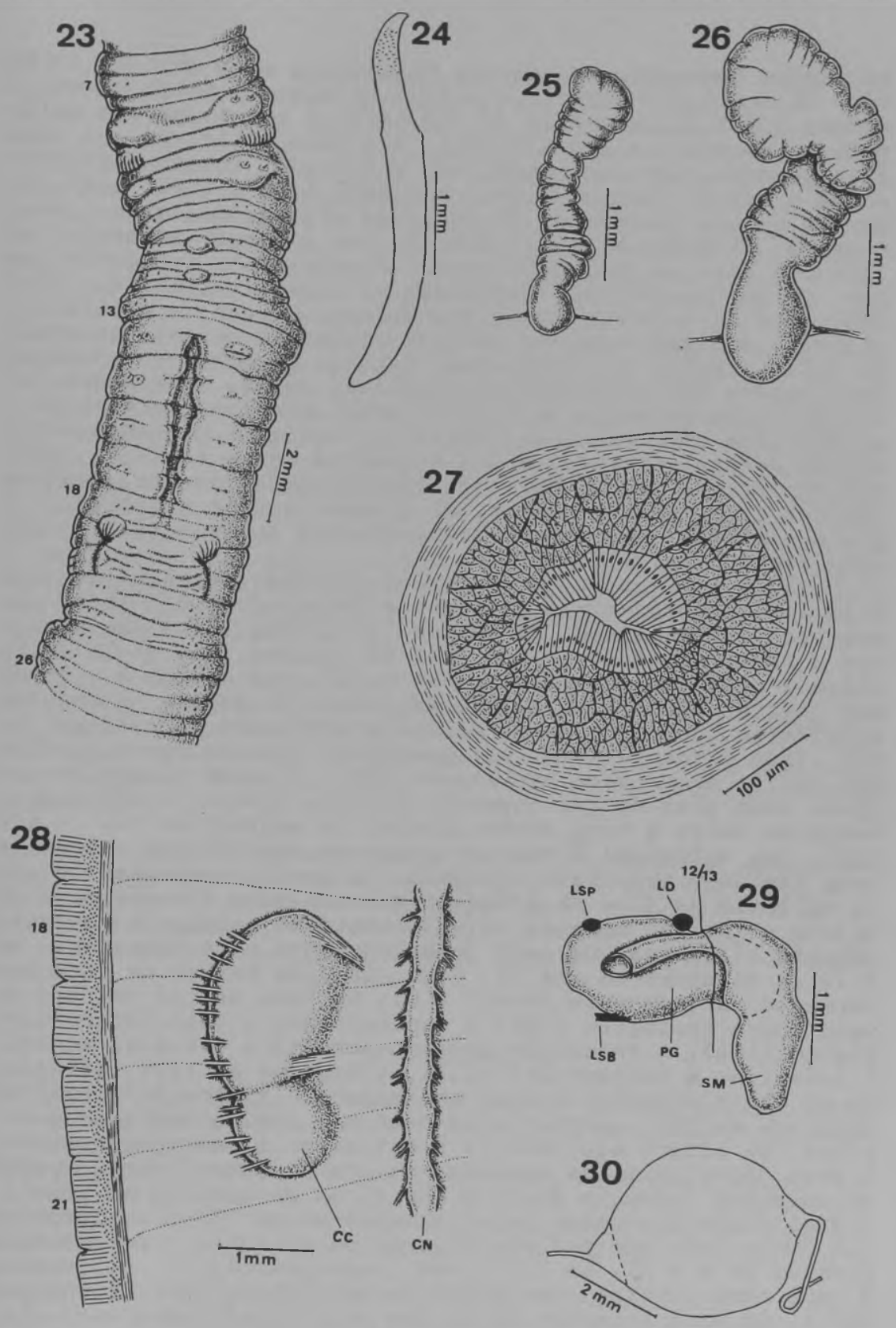
na regiāo posterior (segmentos $\operatorname{CLXXX}-\mathrm{CC}$ ), $a a: a b: b c: c d$ : $d d=16,5: 1,0: 4,2: 1,0: 19,5$. 0 clitelo ocupa os seg mentos $1 / 2$ XIII, XIV-XXII $(=9-9(1 / 2)$, é aberto por um sulco mediano ventral em $1 / 2$ XIV-XVII, 1/2 XVIII (Fig. 23) Uma área quadrangular, esbranquiçada e sulcada transversalmente ocupa o espaço ventral entre as cerdas $b$ de $1 / 2$ XVIII-XX. Um par de sulcos profundos, em forma de arco ou da letra $L$ in vertida, estende-se de $1 / 2$ XIX-XX, com a margem lateral na linha $b$, suas margens podem estar ligeiramente tumefatas ou não. Os sulcos são mais profundos na parte lateral de $1 / 2$ $\mathrm{XIX}$, onde se abrem os poros masculinos. Um par de papilas vo lumosas, ovóides e de cor leitosa contem as cerdas ventrais de VIII em todos os exemplares. Papilas de forma e posição semelhantes são de ocorrencia variavel em IX, onde podem estar bem diferenciadas ou terem desenvolvimento assimétrico, ou faltarem completamente. Papilas circulares pequenas con têm as cerdas ventrais de $1-3$ segmentos entre XI-XV, mais frequentemente em XII-XIII, ou faltam completamente. Papilas impares e medianas ventrais, de forma circular a ovóide e pouco elevadas, ocorrem em 2-4 segmentos entre X-XIII, são mais frequentes em XI-XIII.

Todos os septos têm inserção parietal regular, os $5 / 6$ e 11/12 e seguintes são delgados e frágeis, os 6/7-10/11 são espessos e musculosos. Os septos $5 / 6-11 / 12,12 / 13$ são côni cos e pouco alongados, para trás são planos. Uma moela cilín drica e muito musculosa situa-se em VI, mas devido à formá dos septos corresponde ao VII parietal. Um par de glândulas calcíferas sésseis abre-se dorso-lateralmente no esôfago em XII. Cada glândula (Fig. 29) compõe-se de uma parte glandular (PG) e de un saco membranoso (SM) A parte glandular é pouco mais alta do que espessa, perfura o septo $12 / 13$ e es tende-se sobre a face dorso-lateral do esófago em XII - 1/2 XIII. Sua estrutura $\dot{e}$ tubular composta, os tubulos abrem-se numa cavidade principal alongada, de parede membranosa e pou co saliente na face da glândula voltada para o esôfago. A că vidade principal abre-se anteriormente no esófago e posteriormente alarga-se num saco membranoso que pode dobrar-se em XIII ou estender-se até XV Cada glândula recebe na face lateral um ramo do vaso dorsal (LD), na face medial um ramo do vaso supra-esofágico (LSP) e ventralmente o vaso látero-esofägico (LSB). A transição esôfago-intestino situa-se em XVI. 0 intestino è delgado até XXIII, alarga-se em XXIV, atingindo em XXV o diámetro normal posterior. O tiflosole dorsal inicia-se em XVI, apresenta-se como uma lámina ondulada e espessa, de altura equivalente à metade do diâmetro intestinal. 0 vaso dorsal simples comunica-se com o ventral por 3 pares de corações laterais finos e com forma de rosário em VII-IX. o vaso supra-esofágico ímpar estende-se de VII-XII, comunica -se com o vaso ventral por 2 pares de coraçōes intestinais grossos em X e XI. Em XII o vaso supra-esofágico bifurca-se e cada ramo penetra numa glândula calcífera. Vaso subneural falta. Em cada segmento hă um par de holonefrídios vesiculados com nefridióporos intersegmentares alinhados pouco acima da série de cerdas $b$. Um par de testículos e de funis seminais largos, pregueados e de cor branca prateada encontra-se 
em XI, não há saco testicular. Um par de vesículas seminais em forma de fita estreita dobra-se em XII-XIII, sobre e dos lados das glândulas calcíferas. Um par de câmaras copulató rias musculosas prende-se na parede ventral do corpo de 1/2 XVIII-1/2 XXI (Fig. 28, CC) As câmaras são ovóides, alongadas, com forte estrangulamento no terço posterior. Sua mar gem lateral separa-se nitidamente da parede do corpo, a qual se prende por numerosas e finas faixas musculares. A margem medial passa gradualmente à parede do corpo, prendendo-se ainda por poucas e mais largas faixas musculares Um par de ovários e de funis femininos situa-se em XIII. Cada ovário tem a forma de uma lâmina larga com sulcos longitudinais del gados, entre os quais situam-se os ovos que amadurecem em dí reção ao bordo livre. Dois pares de espermatecas abrem-sē por poros diminutos em $a b$ de $7 / 8$ e $8 / 9$ e situam-se em VIII e IX, sendo as do segundo par as maiores. Em cada espermateca (Figs. 25-26) o duto é curto e espesso, seu lumem é revestido por um epitélio cilíndrico alto, envolvido por uma camada formada por grupos de células glandulares granulosas e por uma capa externa de musculatura circular (Fig. 27) A ampola é saquiforme, dobrada ou não, sua parede è muito e irregular mente pregueada e com grupos de células glandulares semelhañ tes às do duto. Não encontrei espermatozóides nas espermatecas e nem na cavidade de XI:

Casulos - Os casulos (Fig. 30) são arredondados, com "vite10" de cor amarela ovo. Os polos, de cor marrom, prolongam se pelos 2 delgados filamentos polares, um dos quais $\bar{e}$ mais de 2 vezes mais longo do que o outro. 0 espaço util dos casu los atinge em média 5,2 × 4,8 mm. Cada casulo maduro contem um embriẵo.

Consideraçōes - Do gênero Diaguita só é conhecida a espécie tipo, Diaguita michaelseni Cordero, 1942, descrita da Argentina: Jujuy. D. vivianeae distingue-se da espécie tipo pelas papilas pubertais, poróforo masculino e espermatecas 0 nome da nova espécie è uma homenagem à biologista, Srta. Viviane Hamoui.

\section{REFERENCIAS}

BEDDARD, F.E., 1982. On some new species of earthworms from various parts of the world. Proc.zool.Soc.Lond., 1892:666 -706 , est. 45-46.

BEDDARD, F.E., 1893. Two new genera and some new species of earthworms. Quart.J.micr.Sc. (NS) 34:243-278, est. 25-26.

COGNETTI DE MARTIIS, L., 1906. Gli 0ligocheti della Regione Neotropicale, II. Mem.R.Accad.Sc.Torino (2) 56:147-262, 2 est.

COGNETTI DE MARTIIS,L., 1908, Lombrichi raccolti dal Cav. Leonardo Fea nelle isole del Capo Verde e nel Golfo di Guinea. Ann.Mus.civ.Hist.nat.Genova (3) 4:79-118.

CORDERO, E.H., 1942. Oligoquetos terrícolas del Museo Argentino de Ciencias Naturales. Anal.Mus.Argent.Cienc.nat. 40:269-293, est. 1-2. 
EISEN, G., 1900. Researches in American 0ligochaeta, with special reference to those of the Pacific coast and adjacent islands. Proc.Calif.Acad.Sc. (3) 8:84-276, est. 514.

GATES, G.E., 1962 Contributions to a revision of the earthworm family Ocnerodrilidae. Rev.Zool.Bot.Afr., 65(3-4) : 247-264.

GATES, G.E., 1972. Burmese earthworms. Trans.Amer.phizos.Soc. (NS) $62(7): 1-326$.

GATES, G.E., 1979. A new genus of larger Ocnerodrilidearth worms in the American Hemisphere. Megadrilogica, $3(9): 162$ -164 .

HORST, R., 1899. Descriptions of earthworms. On a Benhamia species from Paramaribo. Notes Leyden Mus., 21:27-30.

JAMIESON, B.G.M., 1966. Two Ocnerodrilinae (Megascolecidae, Oligochaeta) from East Africa: Nematogenia lacuum (Bed dard, 1893) and Pygmaeodrilus montiskenyae, sp. n. Ann. Mag.nat. Hist. (13) 8:95-107

MICHAELSEN, W., 1890. Beschreibung der von Herrn Dr. Franz Stuhlman in Mundungsgebiet des Sambesi gesammelten Terricolen. Anhangen I-II. Mitt.Mus.Hamburg, 7:21-50, est. 14.

MICHAELSEN, W., 1891. Oligochaeten des naturhistorischen Museums in Hamburg. IV Mitt.Mus.Hamburg: 8:299-340, 1 est.

MICHAELSEN, W., 1892. Terricolen der Berliner zoologischen Sammlung, II. Arch.Naturg., 58(1):209-261, est. 13 .

MICHAELSEN, W., 1895. Zur Kenntnis der Oligochuten. Abh. naturw.Ver. Hamburg, 13:1-37, est. 1 .

MICHAELSEN, W., 1900. Oligochaeta. Das Tierreich 10: XXIX + 575 pp. R. Friedlünder und Sohn, Berlin.

MICHAELSEN, W., 1907. Regenwturmer von Erythraea. Verh. Ver. naturw. Unterh. Hamburg, 13:5-15.

MICHAELSEN, W., 1910 . Vermes.Wiss.Ergeb.Schwed.zool. Exped. Ki limanjaro, Meru und Ungeb. Massais Deutsch-Ost-Afrika, 1905-06, 2(2):1-10, 1 est.

MICHAELSEN, W., 1911. Die Oligochaeten des inneren Ostafrika und ihre geographischen Beziehungen. Deutsch. Zentral-Afri ka Exped. 1907-08, 2, Zool. 1:1-90, est. 1-2.

MICHAELSEN, W., 1913a. Oligochaten vom tropischen und slidlich subtropischen Afrika, I. Zoologica Stuttgart, 26(67):139170 , est. 19.

MICHAELSEN, $w_{.}, 1913 \mathrm{~b}$. Oligochlten vom tropischen und slldlich subtropischen Afrika, II. Zoologica Stuttgart, 26(68): 163 , est. 1-2.

MICHAELSEN, W., 1915. Zentralafrikanische Oligochlten.Ergeb. Zweit.Deuts. Zentral-Afrika Exped. 1910-11, 1, Zool. 8:185 -317 , est. 14-18.

MICHAELSEN, $w ., 1916$. Oligochyten aus dem Naturhistorischen Reichesmuseum zu Stokholm. Ark.f.200l.,10 (9):1-2l.

MICHAELSEN, W., 1918. Die Lumbriciden, mit besonderer Berlack sichtigung der bisher als Familie Glossoscolecidae zusammengefassten Unterfamilien. Zool.Jh.Syst., 41:1-398, est.

MICHAELSEN, W., 1922. Oligochyten aus dem Rijks-Museum van Natuurlijke Historie zu Leiden. Capita Zoologica, I(3): 3 -72 . 
MICHAELSEN', W., 1928. Miscellanea oligochaetologica. Ark. f. 200Z., 20(2):1-15.

MICHAELSEN, W., 1935. Oligochaeten von Belgisch-Kongo. Rev. Zool.Bot.Afr., $27(1): 33-95$.

MULLER, F, 1857. Lumbricus corethrurus, Blirstenschwamz.Arch. Naturg., 23(1):113-116.

OMODEO, P., 1973. Oligochè̀tes de l'Angola. Publ.Cult.Co.Diam. Ang., Lisboa, 87:13-57.

RIGHI, G., 1972. Contribuição ao conhecimento dos Oligochaeta brasileiros. Papéis Avulsos Zool., S. Paulo, 25(1):149 -166 .

RIGHI, G., 1980. On a collection of neotropical Megadrili 0ligochaeta. Stud neotrop. Fauna (no prelo)

RIGHI, G., 1982. Pontoscolex (Oligochaeta, Glossoscolecidae), a new evaluation. Stud.neotrop.Fauna (no prelo).

RIGHI, G., 1984. Oligochaeta Megadrili da Chapada do Guima rães, Mato Grosso. Bolm.Zool., Univ. S. Paulo, 8:17-23.

RIGHI, G. et all., 1978 Oligochaeta (Annelida) do Instituto Nacional de Pesquisas da Amazônia. Acta Amazōnica, 8 (3) Supl. 1:1-49.

ROSA, D., 1895. Viaggio del dottore Alfredo Borelli nella Re publica Argentina e nel Paraguay. Oligocheti terricoli. Bol.Mus.Torino, 10(204):1-3.

ROSA, D., 1896. Terricoli neotropicali. Mem.R.Accad.Sc.Torino ( 2 ) $45: 89-152,1$ est.

SEGUY, E., 1936. Code universel des couleurs. 68 pp.,55 est. Paul Lechevalier éd., Paris.

STEPHENSON, J., 1931. The Oligochaeta from Brazil and Para guay. J.Linn.Soc.London, 37:291-326, est. 16-18 
